\title{
AWI open Life expectancy and disparity: an international comparison of life table data
}

\author{
James W Vaupel, ${ }^{1}$ Zhen Zhang, ${ }^{1}$ Alyson A van Raalte ${ }^{1,2}$
}

To cite: Vaupel JW, Zhang Z, van Raalte AA. Life expectancy and disparity: an international comparison of life table data. BMJ Open 2011;1:e000128. doi:10.1136/ bmjopen-2011-000128

- Prepublication histroy and additional materials for this paper are avaliable online. To view these files please visit the journal online (http:// bmjopen.bmj.com).

Received 23 March 2011 Accepted 17 June 2011

This final article is available for use under the terms of the Creative Commons Attribution Non-Commercial 2.0 Licence; see http://bmjopen.bmj.com

${ }^{1}$ Max Planck Institute for Demographic Research, Rostock, Germany ${ }^{2}$ Department of Public Health, Erasmus MC, University Medical Centre Rotterdam, Rotterdam, the Netherlands

Correspondence to James W Vaupel; jwv@demogr.mpg.de

\section{ABSTRACT}

Objectives: To determine the contribution of progress in averting premature deaths to the increase in life expectancy and the decline in lifespan variation.

Design: International comparison of national life table data from the Human Mortality Database.

Setting: 40 developed countries and regions, 1840-2009.

Population: Men and women of all ages.

Main outcome measure: We use two summary measures of mortality: life expectancy and life disparity. Life disparity is a measure of how much lifespans differ among individuals. We define a death as premature if postponing it to a later age would decrease life disparity.

Results: In 89 of the 170 years from 1840 to 2009 , the country with the highest male life expectancy also had the lowest male life disparity. This was true in 86 years for female life expectancy and disparity. In all years, the top several life expectancy leaders were also the top life disparity leaders. Although only $38 \%$ of deaths were premature, fully $84 \%$ of the increase in life expectancy resulted from averting premature deaths. The reduction in life disparity resulted from reductions in early-life disparity, that is, disparity caused by premature deaths; late-life disparity levels remained roughly constant.

Conclusions: The countries that have been the most successful in averting premature deaths have consistently been the life expectancy leaders. Greater longevity and greater equality of individuals' lifespans are not incompatible goals. Countries can achieve both by reducing premature deaths.

\section{INTRODUCTION}

The increase in life expectancy, from under 40 years in all areas of the world two centuries ago to over 80 years today in many developed countries, has fundamentally improved the human condition. ${ }^{12}$ Equally significant and closely linked to the increase in life expectancy has been the reduction in differences among individuals in the age at death. ${ }^{3-6}$ Even in the most egalitarian societies before the mid-19th century, the fate of most newborns was to die young, although

\section{ARTICLE SUMMARY}

Article focus

- We examined the relationship between high life expectancy and low life disparity.

- We determined the relative importance of premature versus late deaths in increasing life expectancy and reducing life disparity.

- We examined whether policies to increase life expectancy were compatible with those to reduce lifespan variation.

\section{Key messages}

- Most of the gains in life expectancy are the result of reducing disparities in how long people live, by averting premature mortality.

- Progress in reducing death rates for people who live longer than average has had little effect on life disparity levels and has contributed only modestly to life expectancy gains.

- The countries that have been most successful at reducing premature mortality enjoy the highest life expectancies and the greatest equality in individuals' lifespans.

Strengths and limitations

- We are the first to examine this issue using a large, comparable database of 40 developed countries from 1840 to 2009 containing 7056 life tables.

- Our analysis was limited to countries with data of high enough quality to be included in the database.

- Although this database contains high mortality life tables from historic populations, it is unknown whether the patterns we observed would also be seen in contemporary emerging and developing countries.

a fortunate minority survived to old age. Death rates today in health leaders such as Japan, Spain and Sweden, imply that threequarters of babies will survive to celebrate their 75 th birthdays. $^{2}$

The negative correlation between high life expectancy and low lifespan variation has been investigated for several countries, including the USA, ${ }^{4-67}$ England and Wales, ${ }^{7}$ 
Sweden ${ }^{6}$ and Japan. ${ }^{6}$ The correlation is strong, but there are discrepancies. Some countries, notably the USA, have substantially greater lifespan disparity than might be predicted from their high levels of life expectancy. ${ }^{3-5}$

Progress in reducing premature deaths reduces variation in lifespans, whereas progress in reducing deaths at older ages increases variation in lifespans. A recentlydeveloped demographic formula permits ready determination of the ages at which deaths are premature. ${ }^{8} \mathrm{We}$ use this new formula and apply it to a large dataset on developed countries to gain a deeper understanding of the relationship between high life expectancy and low lifespan variation. We find that the countries that have been the most successful in reducing premature deaths, and consequently in reducing lifespan variation, have consistently been the life expectancy leaders.

\section{METHODS}

Our calculations are based on all period life tables of the Human Mortality Database (HMD) from 1840 to the most recent year available in the data set (7056 life tables covering 170 years). ${ }^{2}$ This is a freely available database with reliable, comparable data covering 40 countries and areas (online supplementary table 1 lists the countries or regions and years used in the analysis).

We measure dispersion in age-at-death by the life disparity measure, $e^{\dagger}$ (a technical description is given in the online supplementary appendix). ${ }^{8}{ }^{9}$ Life disparity is defined as the average remaining life expectancy at the ages when death occurs; it is a measure of life years lost due to death. The more egalitarian the lifespan distribution is, the lower the life disparity. In the Swedish female life table for 2008, life expectancy reached 83 years; for those women who survived to age 83, remaining life expectancy was 7.5 additional years. Hence, a death shortly after birth would contribute 83 years, whereas a death at age 83 would contribute 7.5 years. The average of such values over the Swedish female population, weighted by the number of deaths at each age, gives a life disparity of 9 . In 1840, life expectancy for Swedish women was only 46 and life disparity was 24 . Over time, as deaths became concentrated at later ages, the average gap was reduced between the age at which a person died and the remaining lifespans of people who survived beyond this age.

Saving lives (ie, averting deaths) at any age increases life expectancy. Lifespan disparity, on the other hand, narrows or widens depending on the balance between saving lives at 'early' ages, which compresses the distribution of lifespans, and saving lives at 'late' ages, which expands this distribution by increasing the average remaining life expectancy of survivors. Separating the two is a unique threshold age, $a^{\dagger}$, which is generally just below life expectancy. Henceforth, we refer to deaths occurring before the threshold age as 'premature deaths', while those occurring after this age are 'late deaths'. Thus 'premature deaths' according to our definition are defined relative to the mortality level of the population. This is in contrast to other definitions which use a fixed age, for example, age 65; use of a fixed age is problematic over long periods of time. This new definition implies that deaths at surprisingly old ages can be premature deaths. In 2008 deaths up to age 82 were premature deaths for Swedish females (table 1).

Table 1 Countries and regions in the Human Mortality Database $^{2}$ used in our analysis, ranked by female life expectancy for the latest year available

\begin{tabular}{|c|c|c|c|c|c|c|}
\hline \multirow[t]{2}{*}{ Country or region } & \multicolumn{3}{|c|}{ Females } & \multicolumn{3}{|c|}{ Males } \\
\hline & $\mathrm{e}_{0}$ & $e^{\dagger}$ & $\mathrm{a}^{\dagger}$ & $\mathrm{e}_{0}$ & $\mathrm{e}^{\dagger}$ & $a^{\dagger}$ \\
\hline Japan & 86.4 & 9.2 & 85.3 & 79.6 & 10.6 & 78.0 \\
\hline \multirow[b]{2}{*}{ France } & & $(9,1,9,2)$ & $\begin{array}{r}(85.3,85.4) \\
83.8\end{array}$ & $(79.6,79.6)$ & $(10.6,10.6)$ & $(77.9,78.0)$ \\
\hline & $\begin{array}{r}84.4 \\
(84.3,84.4)\end{array}$ & $\begin{array}{l}9.3 \\
(9.3,9.4)\end{array}$ & $\begin{array}{r}83.8 \\
(83.7 .83 .8)\end{array}$ & $\begin{array}{l}777.4 \\
(77.4,77.5)\end{array}$ & $\begin{array}{l}11.4 \\
(11.3,11.4)\end{array}$ & $\begin{array}{r}76.5 \\
(76.5,76.6)\end{array}$ \\
\hline \multirow{2}{*}{ Switzerland } & 84.1 & 9.0 & 83.2 & 79.3 & 10.2 & 78.0 \\
\hline & $(83.9,84.2)$ & $(8.9,9.1)$ & $(83.1,83.4)$ & $(79.2,79.5)$ & $(10.1,10.3)$ & $(77.9,78.3)$ \\
\hline Italy & 84.1 & 8.8 & 82.9 & 78.8 & 10.2 & 77.3 \\
\hline & $(84.0,84.1)$ & $(8.8,8.9)$ & $(82.8,82.9)$ & $(78.8,78.9)$ & $(10.1,10.2)$ & $(77.2,77.3)$ \\
\hline Spain & 84.1 & 8.8 & 82.9 & 77.6 & 11.1 & 76.0 \\
\hline & $(84.0,84.1)$ & $(8.7,8.8)$ & $(82.9,83.0)$ & $(77.5,77.6)$ & $(11.0,11.1)$ & $(76.0,76.1)$ \\
\hline Australia & 83.7 & 9.3 & 82.9 & 79.3 & 10.6 & 78.0 \\
\hline & $\begin{array}{l}(83.7,83.8) \\
83.1\end{array}$ & $\begin{array}{l}(9.2,9.3) \\
9.1\end{array}$ & $\begin{array}{r}(82.8,83.0) \\
82.4\end{array}$ & $\begin{array}{l}(79.2,79.4) \\
76.5\end{array}$ & $\begin{array}{l}(10.5,10.6) \\
11.2\end{array}$ & $\begin{array}{l}(77.9,78.1) \\
75.3\end{array}$ \\
\hline Finland & $(83.0,83.3)$ & $(0.0,9.2)$ & $(82.2,82.6)$ & $(76.3,76.7)$ & $(11.1,11.3)$ & $(75,1,75.5)$ \\
\hline Sweden & 83.1 & 8.9 & 82.2 & 79.1 & 9.8 & 77.9 \\
\hline Sweden & $(83.0,83.2)$ & $(8.8,8.9)$ & $(82.1,82.3)$ & $(79.0,79.2)$ & $(9.7,9.8)$ & $(77.7,78.0)$ \\
\hline Austria & 83.0 & 8.9 & 82.1 & 77.6 & 10.6 & 76.6 \\
\hline Austria & $(82.9,83.0)$ & $(8.8,8.9)$ & $(82.0,82.2)$ & $(77.5,77.7)$ & $(10.5,10.7)$ & $(76.4,76.8)$ \\
\hline Norway & 83.0 & 9.1 & 81.9 & 78.3 & 10.0 & 77.2 \\
\hline Norway & $(82.8,83.1)$ & $(9.0,9.2)$ & $(81.7,82.0)$ & $(78.2,78.5)$ & $(9.9,10.1)$ & $(77.0,77.4)$ \\
\hline Iceland & 83.0 & 8.7 & 81.9 & 79.7 & 9.8 & 78.2 \\
\hline Icelana & $(82.5,83.7)$ & $(8.3,9.1)$ & $(81.4,82.6)$ & $(79.0,80.4)$ & $(9.3,10.3)$ & $(77.1,79.2)$ \\
\hline Canada & 82.9 & 10.0 & 81.9 & 78.3 & 11.0 & \\
\hline Canada & $(82.9,83.0)$ & $(9.9,10.0)$ & $(81.8,82.0)$ & $(78.3,78.4)$ & $(10.9,11.0)$ & $(76.8,77.0)$ \\
\hline Israel & 82.9 & 9.2 & 81.1 & 79.0 & 10.9 & 77.0 \\
\hline IStact & $(82.7,83.0)$ & $(9.1,9.3)$ & $(81.0,81.3)$ & $(78.8,79.2)$ & $(10.7,11.0)$ & $(76.8,77.2)$ \\
\hline England \& Wales & $\begin{array}{r}82.5 \\
(82.825\end{array}$ & $\begin{array}{r}9.8 \\
(9.9 .8\end{array}$ & $\begin{array}{r}81.1 \\
(81.1812\end{array}$ & $\begin{array}{r}78.3 \\
(783.784\end{array}$ & $\begin{array}{r}10.9 \\
(10.909\end{array}$ & $\begin{array}{r}76.6 \\
(76.667\end{array}$ \\
\hline & $\begin{array}{l}82.4,8.2) \\
82.4\end{array}$ & $\begin{array}{r}(9.8,9.8) \\
8.9\end{array}$ & $\begin{array}{r}(81.1,81.2) \\
81.7\end{array}$ & (78., 77.5 & $\begin{array}{l}(10.9,10.9) \\
10.5\end{array}$ & \\
\hline West Germany & $\begin{array}{r}82.4 \\
(82.4,82.5)\end{array}$ & $\begin{array}{r}8.9 \\
(8.9,9.0)\end{array}$ & $(81.7,81.8)$ & $(77.5,77.6)$ & $(10.4,10.5)$ & $(76.0,76.1)$ \\
\hline & & 9.1 & 81.2 & 76.5 & 11.0 & \\
\hline East Germany & $(82.2,82.5)$ & $(9.0,9.1)$ & $(81.1,81.2)$ & $(76.4,76.6)$ & $(10.9,11.1)$ & $(74.7,74.9)$ \\
\hline & & 8.9 & 81.5 & 76.4 & 11.0 & \\
\hline Portugal & $(82.4,82.5)$ & $(8.8,8.9)$ & $(81.4,81.6)$ & $(76.3,76.5)$ & $(10.9,11.0)$ & $(75.3,75.6)$ \\
\hline Belgium & 82.3 & 9.5 & 81.6 & 76.9 & 10.9 & 75.7 \\
\hline Belgium & $(82.2,82.4)$ & $(9.4,9.5)$ & $(81.5,81.7)$ & $(76.8,77.0)$ & $(10.8,10.9)$ & $(75.5,75.8)$ \\
\hline Netherlands & 82.3 & 9.6 & 80.9 & 78.3 & 9.8 & 76.7 \\
\hline Netherlands & $(82.3,82.4)$ & $(9.5,9.7)$ & $(80.8,81.0)$ & $(78.2,78.4)$ & $(9.8 .9 .9)$ & $(76.6,76.8)$ \\
\hline Slovenia & 82.2 & 8.9 & 81.0 & 75.7 & 11.0 & 73.9 \\
\hline Slovenia & $(82.0,82.5)$ & $(8.8,9.1)$ & $(80.7,81.2)$ & $(75.5,76.0)$ & $(10.8,11.2)$ & $(73.5,74.2)$ \\
\hline & 82.1 & 9.2 & 81.4 & 76.6 & 10.0 & 76.0 \\
\hline Luxembourg & $(81.6,82.6)$ & $(8.9,9.6)$ & $(80.8,82.0)$ & $(76.1,77.2)$ & $(9.7,10.4)$ & $(75.2,76.7)$ \\
\hline New Zealand non-Mari & 82.1 & 9.6 & 81.2 & 77.8 & 10.4 & 76.6 \\
\hline New Zealand non-Maor & $(81.9,82.3)$ & $(9.4,9.7)$ & $(81.0,81.4)$ & $(77.6,78.0)$ & $(10.3,10.6)$ & $(76.3,76.8)$ \\
\hline Taiwan & 82.0 & 10.1 & 80.5 & 75.9 & 12.6 & 73.7 \\
\hline Taiwan & $(81.9,82.1)$ & $(10.0,10.2)$ & $(80.4,80.6)$ & $(75.8,76.0)$ & $(12.5,12.7)$ & $(73.6,73.9)$ \\
\hline Ireland & 81.9 & 9.4 & 80.3 & 77.3 & 10.2 & 75.5 \\
\hline Ireland & $(81.7,82.1)$ & $(9.3,9.6)$ & $(80.1,80.6)$ & $(77.1,77.4)$ & $(10.1,10.4)$ & $(75.3,75.8)$ \\
\hline Northern Ireland & 81.3 & 9.9 & 80.6 & 77.2 & 11.0 & 76.1 \\
\hline Northern Ireland & $(81.0,81.6)$ & $(9.7,10.1)$ & $(80.3,80.9)$ & $(76.9,77.5)$ & $(10.8,11.3)$ & $(75.7,76.4)$ \\
\hline Denmark & 80.9 & 9.9 & 79.4 & 76.5 & 10.7 & 74.9 \\
\hline Denmark & $(80.8,81.0)$ & $(9.8,10.0)$ & $(79.2,79.6)$ & $(76.3,76.6)$ & $(10.6,10.8)$ & $(74,7,75.1)$ \\
\hline USA & 80.8 & 11.1 & 79.8 & 75.6 & 12.5 & 74.5 \\
\hline USA & $(80.7,80.8)$ & $(11.0,11.1)$ & $(79.8,79.8)$ & $(75.6,75.6)$ & $(12.5,12.5)$ & $(74.4,74.5)$ \\
\hline Chile & 80.7 & 10.7 & 78.9 & 75.0 & 12.7 & 72.3 \\
\hline Cnile & $(80.6,80.8)$ & $(10.6,10.8)$ & $(78.8,79.0)$ & $(74.9,75.1)$ & $(12.5,12.8)$ & $(72.0,72.5)$ \\
\hline Scotland & 80.4 & 10.3 & 78.9 & 75.9 & 11.6 & 74.0 \\
\hline scouland & $(80.3,80.6)$ & $(10.2,10.4)$ & $(78.7,79.1)$ & $(75.7,76.0)$ & $(11.5,11.7)$ & $(73.8,74.2)$ \\
\hline Czech Republic & 80.3 & 9.3 & 78.9 & 74.0 & 11.2 & 71.7 \\
\hline & $(80.2,80.4)$ & $(9.2,9.4)$ & $(78.8,79.0)$ & $(73.9,74.1)$ & $(11.2,11.3)$ & $(71.6,71.9)$ \\
\hline Estonia & 80.0 & 9.9 & 79.0 & 69.7 & 12.9 & 66.3 \\
\hline & $(79.7 .80 .3)$ & $(9.6,10.1)$ & $(78.8,79.3)$ & $(69,4,70,1)$ & $(12.7,13.2)$ & $(65.8,66.9)$ \\
\hline Poland & 79.9 & 10.0 & 78.9 & 71.5 & 12.5 & 68.7 \\
\hline & $(79.8,80.0)$ & $(9.9,10.0)$ & $(78.8,79.0)$ & $(71.4,71.5)$ & $(12.5,12.6)$ & $(68.6,68.8)$ \\
\hline Slovakia & $\begin{array}{r}78.8 \\
(78.7 .79 .0)\end{array}$ & $\begin{array}{r}9.8 \\
(9.6,9.9)\end{array}$ & $\begin{array}{r}77.2 \\
(77.0 .77 .3)\end{array}$ & $\begin{array}{r}70.8 \\
(70.6,71.0)\end{array}$ & $\begin{array}{r}12.2 \\
(12.1,12.3)\end{array}$ & $\begin{array}{r}67.8 \\
(67.6 .68 .0)\end{array}$ \\
\hline Lithuania & 78.6 & 10.2 & 78.0 & 67.5 & 13.6 & 64.0 \\
\hline China ${ }^{*}$ & & $(10,1,10.4)$ & $(77.8,78.2)$ & $(67.3,67.7)$ & $(13.4,13.7)$ & $(63.6,64.3)$ \\
\hline & 78.2 & 11.7 & 76.5 & 73.4 & 12.6 & 72.0 \\
\hline Latvia & 78.0 & 10.5 & 77.5 & 68.3 & & 64.8 \\
\hline & $(77.8,78.3)$ & $(10.4,10.7)$ & $(77.2,77.7)$ & $(68.0,68.5)$ & $(13.0,13.3)$ & $(64.5,65.1)$ \\
\hline Hungary & 77.7 & 10.7 & 76.1 & 69.2 & 12.9 & 65.0 \\
\hline & $(77.5,77.8)$ & $(10.7,10.8)$ & $(76.0,76.2)$ & $(69.0,69.3)$ & $(12.8,13.0)$ & $(64,8,65.1)$ \\
\hline Bulgaria & $\begin{array}{r}77.3 \\
\end{array}$ & 10.1 & 76.3 & 70.0 & 12.6 & 67.3 \\
\hline Belonvs & $\begin{array}{r}(77.1,777.4) \\
76.1\end{array}$ & $(10.0,10.2)$ & $(76.1 .76 .4)$ & $(69.9 .70 .2)$ & $\begin{array}{r}(12.5,12.7) \\
13.7\end{array}$ & $\begin{array}{l}(67.2,67.5) \\
604\end{array}$ \\
\hline Belarus & $(76.0,76.3)$ & $(10.8,11.0)$ & $(74.6,74.9)$ & $\begin{array}{l}(64.4,64.77) \\
-\end{array}$ & $(13.6,13.7)$ & 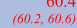 \\
\hline Russia & & 11.9 & 73.4 & 61.8 & 15.0 & 57.4 \\
\hline Russia & $(74,1,74,2)$ & $(11.9,11.9)$ & $(73.4,73.5)$ & $(61.7,61.8)$ & $(15.0,15.1)$ & $(57,3,57,4)$ \\
\hline Ukraine & 73.8 & 11.6 & 72.9 & 62.3 & 14.7 & 58.0 \\
\hline Ukraine & $(73.7,73.9)$ & $(11.6,11.7)$ & $(72.8,72.9)$ & $(62.2,62.4)$ & (14.7, 14.8) & $(57.9,58.0)$ \\
\hline India* & 63.8 & 18.2 & 72.8 & 61.8 & 18.2 & 69.7 \\
\hline South Africa ${ }^{\circ}$ & 52.6 & 20.7 & 60.6 & 50.0 & 19.8 & 56.8 \\
\hline
\end{tabular}

All other data are from the Human Mortality Database 2011. See online supplementary table 1 for latest year available. Life expectancy is denoted by $e_{0}$, the threshold age separating 'premature' from 'late' deaths by $a^{\dagger}$, and life disparity by $e^{\dagger}$, with $95 \%$ Cls given in brackets (see supplementary material). Information for Eastern European countries is shown in red and for the USA in blue. The countries used in our analyses are in regular type face. The countries in italics have less reliable data and are shown for comparison only; data for these countries comes from the WHO database 2006 and were not included in the analyses. *Data sources: data for 2006 from WHO, not used in the analysis but shown here for comparative purposes. 
The life disparity measure has the property that it can be additively decomposed at any age such that the components before and after this age sum to the total life disparity. ${ }^{8}$ When it is decomposed at the threshold age, the components are defined as 'early-life disparity' and 'late-life disparity'.

While it is known that high life expectancy is associated with low lifespan variation, we wanted to establish whether life expectancy leaders had the most egalitarian lifespan distributions. For each sex, year, and for up to 40 countries depending on the year, we determined the male and female record high life expectancy and record low life disparity. We calculated how many fewer years of life expectancy and additional years of life disparity each country experienced compared with the record-holding country in that year.

We next investigated the relative importance of premature versus late deaths in determining the relationship between high life expectancy and low life disparity. To do so, we calculated first the number of premature and late deaths as a proportion of all deaths, measured by 10 -year averages across all countries and years. We then compared this to the respective contributions of averting premature and late deaths to increases in life expectancy, ${ }^{8}{ }^{9}$ using a 20 -year moving average to smooth mortality trends over exceptional years of war, pandemics or famine (see the online supplementary appendix for a technical description).

Finally, we ranked countries according to their life expectancy and life disparity for the latest year for which we had data.

\section{RESULTS}

Populations with high life expectancy enjoy low life disparity. In 89 out of 170 years, holders of record life expectancy for males also enjoyed the lowest life disparity (figure 1). For females this happened 86 times (see online supplementary figure 1). More generally, the country with record life expectancy usually had an exceptionally low life disparity and vice versa. This is remarkable because life expectancy is a measure of the average length of life and life disparity is a measure of variation among individuals in the length of life. In principle, the two measures could be unrelated to each other. The set of countries with the highest life expectancies could be completely different from the set of countries with the lowest life disparities, but it turns out that the two sets largely overlap.

The most successful countries increased life expectancy not because of a general decrease in mortality at all ages, but because of a decrease in premature mortality. Figure 2 shows that the reduction in life disparity-from around 25 years in 1840 to between 9 and 15 years at present-is overwhelmingly due to reductions in earlylife disparity caused by tackling premature mortality. Although mortality rates at old ages have come down considerably (which might cause one to expect increases in late-life disparity), the shifting of the threshold age to

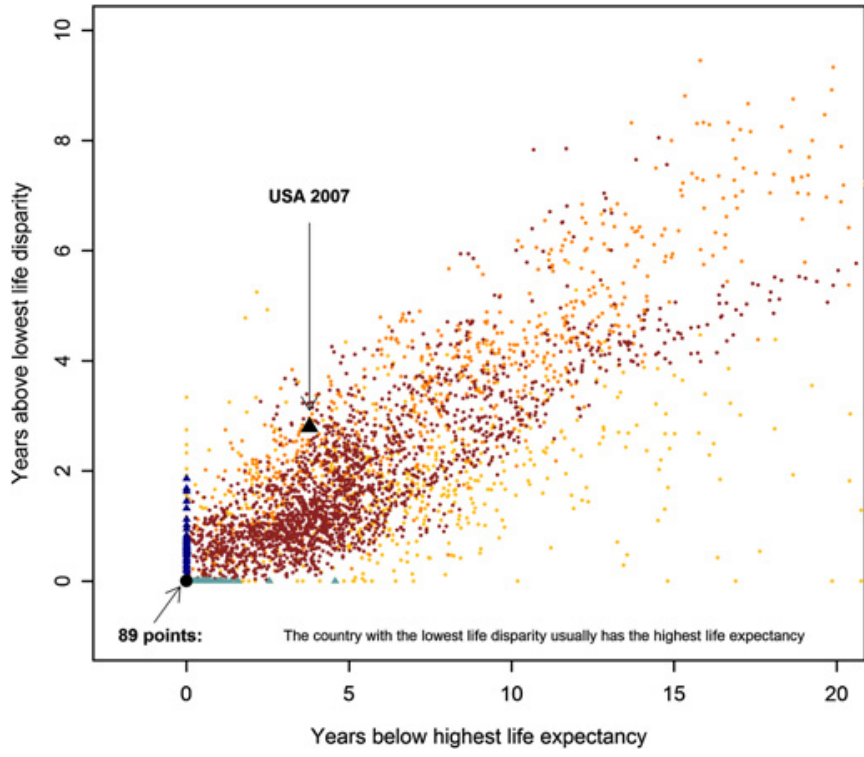

Figure 1 The association between life disparity in a specific year and life expectancy in that year for males in 40 countries and regions, 1840-2009 (see online supplementary table 1). The correlation coefficient between them is 0.77 (95\% Cl 0.76 to 0.78 ). The black triangle represents the USA in 2007 ; the USA had a male life expectancy 3.78 years lower than the international record in 2007 and a life disparity 2.8 years greater. The brown points denote years after 1950, the orange points 1900-1949 and the yellow points 1840-1900. The light blue triangles represent countries with the lowest life disparity but with a life expectancy below the international record in the specific year; the dark blue triangles indicate the life expectancy leaders in a given year, with life disparities greater than the most egalitarian country in that year. The black point at $(0,0)$ marks countries with the lowest life disparity and the highest life expectancy. During the 170 years from 1840 to 2009, 89 holders of record life expectancy also enjoyed the lowest life disparity. The equivalent figure for females is presented in online supplementary figure 2.

higher ages has caused late-life disparity to stay roughly constant at around or just under 5 years.

For females since 1840 , premature deaths have accounted for only $38 \%$ of all deaths, but fully $84 \%$ of the increase in life expectancy resulted from decreases in premature deaths (see online supplementary figure 2). During this time the threshold age rose considerably, rising from 47 for Swedish women in 1840 to 85 for Japanese women in 2009. Historically (and today in less developed countries), infants, children and younger adults suffered most premature deaths. In today's more developed countries, premature deaths have shifted primarily to older adults in their $60 \mathrm{~s}$ and $70 \mathrm{~s}$. The rise in the threshold age is highly correlated with the rise in life expectancy: the correlation coefficient is 0.96 for males and 0.98 for females.

Table 1 displays the latest life expectancy, threshold age and life disparity calculated for each country. In Russia, life expectancy is extraordinarily low and life disparity is very high. In the USA, life expectancy is much greater than in Russia but short compared to other 


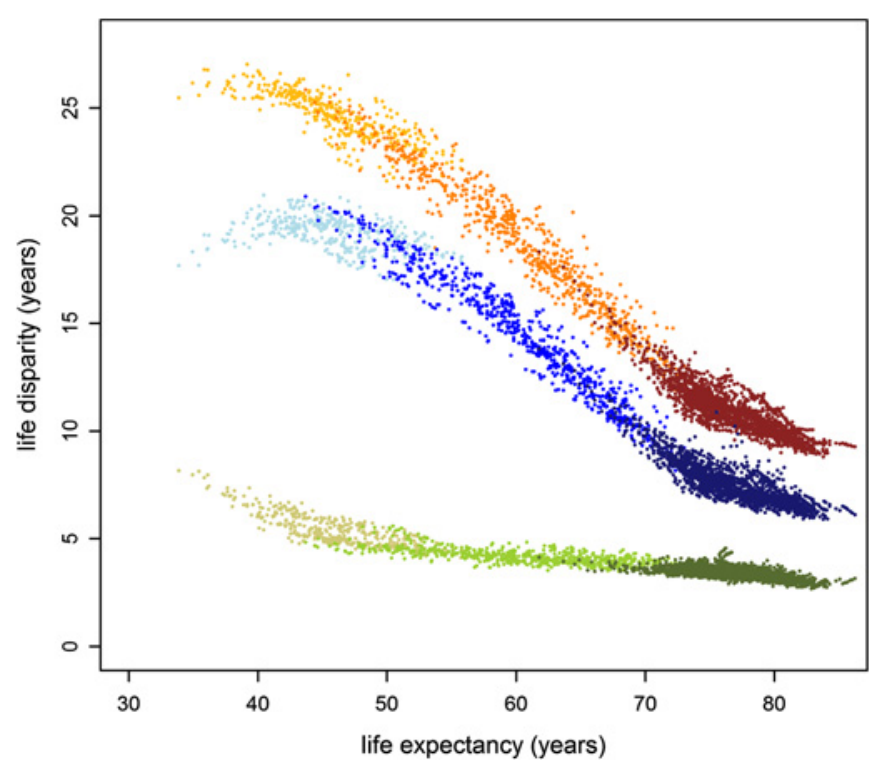

Figure 2 The relationship between total life disparity (red), early-life disparity up to the threshold age (blue) and late-life disparity after the threshold age (green). The darkest hues relate to data from 1950-2009, middle hues 1900-1949 and lightest hues 1840-1899. Total disparity is an additive function of early-life disparity and late-life disparity. Since 1840 the decrease in total life disparity has resulted from reductions in early-life disparity. The correlation coefficient between earlylife disparity and total life disparity is $0.997(95 \% \mathrm{Cl} 0.997$ to $0.997)$. Late-life disparity has remained remarkably constant at about 5 years across a wide range of life expectancies. Hence, according to this measure, there has been neither a marked compression nor expansion of mortality at advanced ages as life expectancy has increased. Data are for females from the 40 countries and regions of the Human Mortality Database (see online supplementary table 1).

highly developed countries. Females in most Eastern European countries, and males in some of them, do better than the USA in life disparity and hence face more certainty in their lifetimes. In contrast, Japanese females are remarkably successful. They hold the record for life expectancy, 86.4 years in the life table for 2009. Half of deaths occurred after age 88 and the most common age of death was 93: deaths up to age 85 were premature in the sense that averting such deaths would decrease life disparity.

\section{DISCUSSION}

These findings make clear that the correlation between high life expectancy and low lifespan variation is due to progress in reducing premature mortality. The countries that have the highest life expectancy today are those which have been most successful at postponing the premature deaths that contribute to early-life disparity.

In addition to life disparity, several other measures of

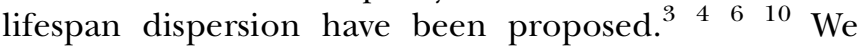
analysed the extent to which our findings depend on our use of life disparity as our measure of lifespan variation. We calculated Pearson correlation coefficients between pairs of the more commonly used measures of lifespan variation, based on all male and female period life tables available from the Human Mortality Database (see online supplementary table 1). As shown in online supplementary table 2, these measures are highly correlated with each other. In particular, the correlation of life disparity with the other measures never falls below 0.966 for females and 0.940 for males. Hence, life disparity can be viewed as a surrogate for the other measures. Although the various measures are highly correlated, they differ somewhat in their sensitivity to deaths at different ages in the lifespan distribution. ${ }^{4} 11$ The use of an alternate measure of lifespan variation would result in some changes in the ranking of countries with similar life disparity levels, but the high correlation between measures implies that such changes would be minor.

Some researchers have examined whether lifespan variation above the adult modal age at death has changed with increased survivorship. These studies also tend to find a gradual decline in later life mortality variation. ${ }^{10}{ }^{12-14}$ Exploring the relationship between life disparity and compression around the modal age at death is a promising avenue for further research. More generally, whether expansion or compression of the lifespan distribution is observed over time can depend on the age range examined. ${ }^{15-17}$ While being a life expectancy leader is associated with low life disparity when the entire lifetime is examined, this relationship might not hold for selected age ranges.

Reducing early-life disparities helps people plan their less-uncertain lifetimes. A higher likelihood of surviving to old age makes savings more worthwhile, raises the value of individual and public investments in education and training, and increases the prevalence of long-term relationships. Hence, healthy longevity is a prime driver of a country's wealth and well-being. ${ }^{18}$ While some degree of income inequality might create incentives to work harder, premature deaths bring little benefit and impose major costs. ${ }^{19}$

Moreover, equity in the capability to maintain good health is central to any larger concept of societal justice. ${ }^{20}$ The tenet that everyone should be entitled to a long, healthy lifespan has gained support as mortality at younger ages has declined. Currently, rates of change for adult mortality vary more across countries than those for infants and children. ${ }^{21}$ In Williams' concept of "fair innings", ${ }^{22}$ individuals dying early are "cheated", while those living beyond a "normal" lifespan are "living on borrowed time". Groups and areas with lower socioeconomic status account for a disproportionate share of lifespan variation, ${ }^{347}$ which compounds the inequity of premature death.

If death rates continue to decline, most babies born in advanced nations today may live to enjoy their 100th birthday. ${ }^{23}$ As we celebrate this progress in extending lives, it is reasonable to question whether we ought to continue aiming for ever longer lives on average or 
Figure 3 The relationship between remaining life expectancy at age $15\left(e_{15}\right)$ and life disparity at age 15 , according to the year in which $e_{15}$ was first reached. Up until 1960 and for $e_{15}$ from 54 to 59 , the pioneers in first attaining a level of remaining life expectancy did so with higher levels of life disparity than the laggards. Since 1960 and at higher remaining life expectancies, the relationships between remaining life expectancy and life disparity at age 15 are not correlated. Ages 15 and over were examined to make the results comparable to those obtained by Smits and Monden. ${ }^{5}$ Data are for females from the 40 countries and regions in the Human Mortality Database (see supplementary online table 1)
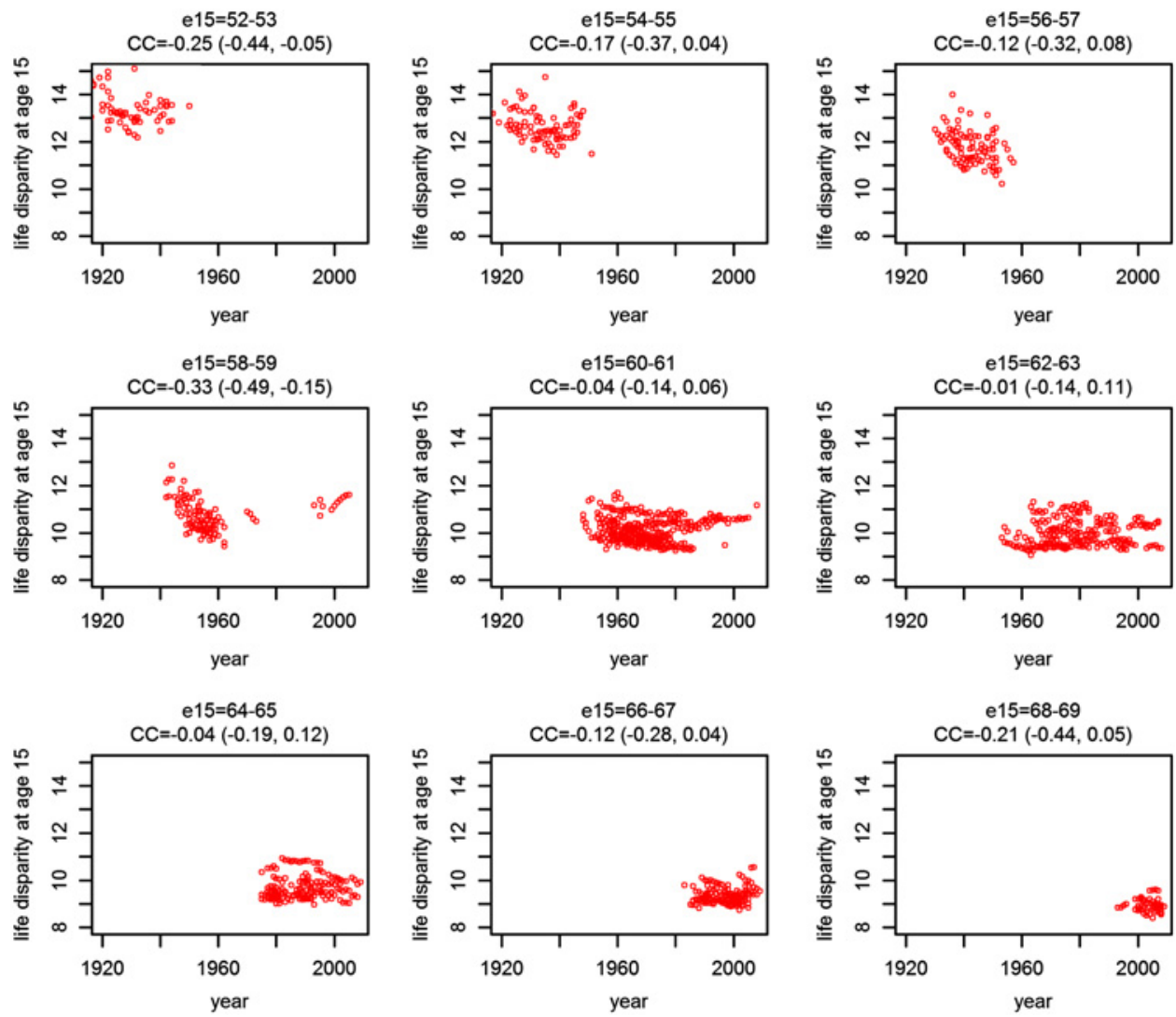

should ensure that more individuals avoid premature death. Policymakers face a choice of where to target healthcare spending. Reducing life disparity would lead to health policies that prioritise early mortality and to social protection schemes designed to shield vulnerable individuals and groups. We are not the first to make this argument. Heath poignantly reasoned that if healthcare services were serious about reducing health inequality, they should direct their attentions to reducing premature mortality-even if this meant reducing expensive medical treatments for the elderly. ${ }^{24}$ The accompanying editorial in $B M J$ proclaimed that "premature deaths should be the priority for prevention". 25

Russia, the USA and other laggards can learn much from research on the reasons why various countries (including Japan, France, Italy, Spain, Sweden and Switzerland) have been more successful in reducing premature deaths. The reasons involve healthcare, social policies, personal behaviour (especially cigarette smoking and alcohol abuse), and the safety and salubriousness of the environment. ${ }^{26-33}$ Genetic variation plays a modest role in determining variation in how long we live ${ }^{34} 35$ and cannot account for the major declines in life disparity and increases in life expectancy or the large differences in life expectancy and disparity among countries.

Smits and Monden ${ }^{5}$ recently showed that countries achieving some level of life expectancy earlier than others did so with higher levels of lifespan variation. This led them to conclude that "reducing inequality and gaining increases in life expectancy might be alternative goals that require different policy measures to be achieved". Our results differ because we examine differences between countries in lifespan variation for each year, whereas they examine differences over time in lifespan variation within each country. These different set-ups can lead to different conclusions. In a study comparing the USA to England and Wales, reductions in circulatory diseases were causing most of the changes in lifespan variation over time (in each country), whereas differences in external mortality explained much of the difference in life disparity between countries at any given time. ${ }^{7}$ As can be seen in figure 3, the relationship between being pioneers in life expectancy and having high life disparity is weak, especially after 1960. We take issue with Smits and Monden's conclusion, which our cross-sectional results do not support. Over the past 170 years, the country with the lowest life disparity most often had the highest life expectancy. Even today, the most egalitarian countries are all among the longest living.

The increase in life expectancy is given by the product of two factors-life disparity and the rate of progress in reducing age-specific death rates. ${ }^{9}$ The lower life disparity is, the greater is the rate of progress needed to quently, it might be thought that countries would aim for life expectancy increases by maintaining high levels of inequality in the lifespan distribution. The opposite is true (figure 1). The reason is that the countries with achieve an additional year of life expectancy. Conse- 
long life expectancy have gained this victory by focusing on reductions in premature deaths-and reductions in premature deaths reduce life disparity. It is not a question of either long life or low disparity: countries can achieve both by averting premature deaths.

Acknowledgements We thank A Baudisch, JR Goldstein, E Loichinger, J Oeppen, VM Shkolnikov, KW Wachter and H Wilkoszewski for helpful comments. We are grateful to V Canudas-Romo, A Leyland and M Murphy for reviewing the paper.

Funding This work was supported by the Max Planck Society and the US National Institute on Ageing (NIA P01-08761).

\section{Competing interests None.}

Contributors JWV conceived the research idea and co-wrote the drafts, ZZ managed the data analysis and commented on the drafts, and AAvR contributed to data analysis and co-wrote the drafts. All authors approved the final manuscript.

Provenance and peer review Not commissioned; externally peer reviewed.

Data sharing statement Data from the Human Mortality Database are freely available at http://www.mortality.org.

\section{REFERENCES}

1. Oeppen J, Vaupel JW. Broken limits to life expectancy. Science 2002;296:1029-31.

2. Human Mortality Database. University of California, Berkeley (USA), and Max Planck Institute for Demographic Research (Germany). http://www.mortality.org.

3. Edwards RD, Tuljapurkar S. Inequality in life spans and a new perspective on mortality convergence across industrialized countries. Popul Dev Rev 2005;31:645-74.

4. Shkolnikov V, Andreev E, Begun AZ. Gini coefficient as a life table function. Computation from discrete data, decomposition of differences and empirical examples. Demogr Res 2003;8:305-58.

5. Smits J, Monden C. Length of life inequality around the globe. Soc SciMed 2009;68:1114-236.

6. Wilmoth JR, Horiuchi S. Rectangularization revisited: variability of age at death within human populations. Demography 1999;36:475-95.

7. Shkolnikov VM, Andreev EM, Zhang Z, et al. Losses of expected lifetime in the US and other developed countries: methods and empirical analysis. Demography 2011;48:211-39.

8. Zhang $Z$, Vaupel JW. The age separating early deaths from late deaths. Demogr Res 2009;20:721-30.

9. Vaupel JW, Canudas Romo V. Decomposing change in life expectancy: a bouquet of formulas in honor of Nathan Keyfitz's 90th Birthday. Demography 2003;40:201-16.

10. Cheung SL, Robine JM, Tu EJ, et al. Three dimensions of the survival curve: horizontalization, verticalization, and longevity extension. Demography 2005;42:243-58.

11. Anand $S$, Diderichsen $F$, Evans $T$, et al. Measuring disparities in health: methods and indicators. In: Evans T, Whitehead M, Diderichsen $\mathrm{F}$, et al, eds. Challenging Inequities In Health: From Ethics To Action. New York: Oxford University Press, 2001.
12. Thatcher AR, Cheung SLK, Horiuchi S, et al. The compression of deaths above the mode. Demogr Res 2010;22:505-38.

13. Cheung SL, Robine JM. Increase in common longevity and the compression of mortality: the case of Japan. Popul Stud (Camb) 2007;61:85-97.

14. Kannisto V. Mode and dispersion of the length of life. Population 2001;13:159-71.

15. Robine JM. Redefining the stages of the epidemiological transition by a study of the dispersion of life spans: the case of France. Population 2001;13:173-93.

16. Nusselder WJ, Mackenbach JP. Rectangularization of the survival curve in The Netherlands, 1950-1992. Gerontologist 1996;36:773-82.

17. Engelman M, Canudas-Romo V, Agree EM. The implications of increased survivorship for mortality variation in aging populations. Popul Dev Rev 2010;36:511-39.

18. Bloom DE, Canning D. The health and wealth of Nations. Science 2000;287:1207-9.

19. Anand S. The concern for equity in health. J Epidemiol Community Health 2002;56:485-7.

20. Sen A. Why health equity? Health Econ 2002;11:659-66.

21. Rajaratnam JK, Marcus JR, Levin-Rector A, et al. Worldwide mortality in men and women aged 15-59 years from 1970 to 2010: a systematic analysis. Lancet 2010;375:1704-17.

22. Williams A. Intergenerational equity: an exploration of the fair innings argument. Health Econ 1997;6:117-32.

23. Christensen K, Doblhammer G, Rau R, et al. Ageing populations: the challenges ahead. Lancet 2009;374:1196-208.

24. Heath I. What do we want to die from? BMJ 2010;341:c3883.

25. Godlee F. Premature deaths should be the priority for prevention. BMJ 2010;341:c3946.

26. Doll R, Peto R, Boreham J, et al. Mortality in relation to smoking: 50 years' observations on male British doctors. BMJ 2004;328:1519.

27. Ezzati M, Lopez AD, Rodgers A, et al. Selected major risk factors and global and regional burden of disease. Lancet 2002;360:1347-60.

28. Kauhanen J, Kaplan GA, Goldberg DE, et al. Beer binging and mortality: results from the kuopio ischaemic heart disease risk factor study, a prospective population based study. BMJ 1997;315:846.

29. Lundberg O, Yngwe MA, Stjärne MK, et al. The role of welfare state principles and generosity in social policy programmes for public health: an international comparative study. Lancet 2008;372:1633-40.

30. Marmot M, Friel S, Bell R, et al. Closing the gap in a generation: health equity through action on the social determinants of health. Lancet 2008:372:1661-9.

31. Peto R, Boreham J, Lopez AD, et al. Mortality from tobacco in developed countries: indirect estimation from national vital statistics. Lancet 1992;339:1268-78.

32. Rehm J, Mathers C, Popova S, et al. Global burden of disease and injury and economic cost attributable to alcohol use and alcohol-use disorders. Lancet 2009;373:2223-33.

33. Whitehead M, Dahlgren G. Concepts and Principles For Tackling Social Inequities In Health: Levelling Up Part 1. Copenhagen: WHO 2007:1-45.

34. McGue M, Vaupel JW, Holm NV, et al. Longevity is moderately heritable in a sample of Danish twins born 1870-1880. J Gerontol 1993;48:237-44.

35. Herskind A, McGue M, Holm N, et al. The heritability of human longevity: a population-based study of 2872 Danish twin pairs born 1870-1900. Hum Genet 1996;97:319-23. 